\title{
Knowledge, Attitudes and Behaviours Towards Exclusive Breastfeeding Amongst Mothers in Sarawak, Malaysia: A Qualitative Study
}

Dr Imogen Margaret Buss ${ }^{1}$

${ }^{1}$ Department of Medicine, North Bristol NHS Trust, Brunel Building, Westbury-on-Trym, Bristol, BS10 5NB UK.

\section{ABSTRACT}

Introduction: Exclusive breastfeeding is recommended as the optimal method of infant feeding for the first six months, but the rate remains low in many countries, including Malaysia. It is important to understand barriers preventing exclusive breastfeeding, to enable tackling these issues and thereby improving maternal and child health. This study aims to do this by exploring the knowledge, attitudes and behaviours of mothers towards breastfeeding in Sarawak, Malaysia. Material and Methods: Qualitative methods were employed, using semi-structured interviews with an interpreter, conducted in Sarawak General Hospital between $16^{\text {th }}$ April and $11^{\text {th }}$ May 2012. Convenience sampling was used to recruit participants from the maternity wards. Interviews were conducted using a topic guide, were audio-recorded and transcribed verbatim. Analysis was based on conventional content analysis, with codes and themes developing from the interviews. Results: Analysis of the 17 interviews identified five major themes; (1) positive attitudes towards breastfeeding, (2) lack of knowledge relating to exclusive breastfeeding, (3) fear of insufficient milk, (4) methods to improve awareness and knowledge of breastfeeding, (5) improvements in the workplace. There is a lack of knowledge amongst mothers in Malaysia regarding breastfeeding, causing anxiety and early discontinuation of breastfeeding. Methods to improve education of mothers and healthcare staff have been suggested, as well as improvements to encourage breastfeeding in the workplace. Conclusion: Focused education for new mothers and widespread community education may help improve breastfeeding continuation rates. The provision of workplace facilities and flexible working hours for new mothers may help overcome physical barriers preventing breastfeeding continuation once back at work.

KEYWORDS: Knowledge, Attitude, Behaviour, Breastfeeding, Malaysia

\section{INTRODUCTION}

The multiple advantages of breastfeeding for both mother and child have been widely studied and are well-recognised. ${ }^{1-3}$ This multitude of evidence strongly influenced the formation of guidelines by the World Health Organization (WHO), which recommend exclusive breastfeeding for the first six months of life, then additional food supplementation until two years. ${ }^{4}$ Breastfeeding

Corresponding Author

Dr Imogen M Buss

Department of Medicine,

North Bristol NHS Trust,

Brunel Building, Westbury-on-Trym,

Bristol, BS10 5NB UK

Email: imogenbuss@gmail.com protection, promotion and support are vital contributions to numerous Sustainable Development Goals (SDGs). ${ }^{5}$ Amongst others, it helps improve child nutrition (SDG 2) and health (SDG 3), supports cognitive development and education (SDG 4), as well as enhancing gender equality (SDG 5) and reduce inequalities (SDG 10)..$^{5}$ Despite the WHO guidelines, exclusive breastfeeding prevalence and duration remain below recommendations in many countries worldwide, including Malaysia.

In Malaysia, there was a steady decline in breastfeeding rate and duration from the mid-1950's to mid-1970's. ${ }^{6-8}$ This was influenced by maternal health clinics promoting bottle-feeding and supplying formula milk, ${ }^{9-11}$ as well as some inaccurate beliefs about breastfeeding. ${ }^{12}$ In order to address this issue, the Malaysian government formulated a National Breastfeeding Policy in $1993,,^{13,14}$ following the 
launch of the global Baby-Friendly Hospital Initiative by the United Nations Children's Fund (UNICEF) and the WHO in 1991, to encourage all maternity units to protect, promote and support breastfeeding. ${ }^{15}$ In 1998. Malaysia was the third country worldwide to have accredited all governmental hospitals as baby-friendly. ${ }^{16}$ This implementation improved prevalence, rapid initiation of breastfeeding and continuation up to one year, although the rate of exclusive breastfeeding up to six months remained low $(14.5 \%$ in 2006$) .{ }^{17}$

The classic model linking knowledge, attitudes and behaviour was first presented by Allport. ${ }^{18}$ The model postulated that people acquire information about a behaviour (knowledge), which leads to developing a predisposition to respond to it (attitude), leading to behaviour aligned with this attitude. Definitions of these concepts are complex, but for clarity, we use the following definitions. Knowledge as "all information that a person possesses or accrues related to a field of study", attitude as "emotions and feelings attached to a particular action or though that are related to behaviours" and behaviour as "the way in which a person, organism or group responds to a certain set of conditions". ${ }^{19}$ There is conflicting evidence about whether this model is accurate in practice, but it forms a good basis on which to consider complex situations particularly when focusing on changing behaviour.

By comprehending the knowledge and attitudes of mothers, it may be possible to change infant feeding behaviours. Only one recent qualitative study investigated breastfeeding attitudes and knowledge in Malaysia; it demonstrates negative attitudes and poor knowledge of pregnant women surrounding breast milk expression, which is a useful practice for working mothers. ${ }^{20}$ Other studies conducted in Malaysia highlight the lack of knowledge amongst mothers regarding infant feeding. ${ }^{21-23}$ Although the requirement of further education is evident, there is no consensus on specific education requirements.

It is essential to understand barriers faced by mothers, and factors influencing their decision regarding breastfeeding to aid women to overcome these barriers. The most common reasons given for stopping breastfeeding in Malaysia have been cited as the mother feeling that she has insufficient milk, and maternal employment. ${ }^{24-27}$ Previous evidence demonstrates lower rates of exclusive breastfeeding amongst employed mothers, and modifications to encourage breastfeeding in the workplace have been advised, ${ }^{28,29}$ but insufficient action has been taken.

The primary aim of this study is to investigate knowledge, attitudes and behaviours of mothers towards breastfeeding in Sarawak, Malaysia, focusing on unearthing the reasons behind these opinions and barriers preventing breastfeeding. These terms have been explained above and are formed according to the Allport model. ${ }^{18}$ In addition to practical reasons, Sarawak was selected for this research due to its multi-ethnic society, ${ }^{30}$ and because there is a significant paucity of qualitative research regarding this topic in non-peninsular Malaysia. Qualitative research enables a greater indepth exploration of reasons explaining different aspects of attitude and behaviours, as well as challenging knowledge acquisition. It "seeks to identify what individuals do know...what the underlying rationality of their behaviour is". ${ }^{31}$ The secondary aim of the study is to highlight improvements that could encourage mothers to exclusively breastfeed. By conducting qualitative research in Sarawak, a unique addition to current literature will be provided, obtaining in-depth responses and enabling clarification of concepts.

\section{METHODS}

This hospital-based, cross-sectional, qualitative data collection was conducted between $16^{\text {th }}$ April and $11^{\text {th }}$ May 2012. New or expectant mothers were interviewed with the aid of a translator in the maternity ward in Sarawak General Hospital, Kuching, Sarawak, Malaysia. Convenience sampling selected mothers who were available for interview and who consented to partake in this study. Interviewing continued until data saturation was reached and no new themes emerged. Generalisations cannot be made from these data due to the small sample size.

The semi-structured interviews were based on a topic guide involving open and closed questions. They focused on breastfeeding knowledge, attitudes, behaviours, barriers encountered and suggested improvements. Using the Allport Model, ${ }^{18}$ we can appreciate that these social aspects of life 
are deeply interlinked and exploring them in depth can help to greater understand an individual's viewpoint and actions. Interviews were conducted in a private room adjacent to the maternity ward. Interviews were recorded with verbal consent of each interviewee. Prior to interview, participants were provided with an information sheet, and asked for written consent, in Malay. Participants were informed that the interview would be confidential, and no personal identifiers would be used. Each interview lasted approximately twenty minutes.

Member validation ensures credibility. This was accomplished by providing each mother with a verbal summary of the interview; all agreed with the summaries provided. Consistency was maintained by conducting the interviews in the same environment, and by using the same translator when possible.

Interview transcripts were analysed using an approach based on conventional content analysis. This was suitable because this study aims to describe phenomena where there is a paucity of existing qualitative literature. For this approach, pre-conceived categories are not used, allowing for novel categories to emerge from the data. However, due to the requirement of a translator, it was difficult to strictly follow this analysis because the mother's exact words were not captured during interview. The translator was advised about the importance of translating word-for-word and given ample time to do so during the interviews.

During the analysis, firstly the transcript was read to encourage data immersion, following which codes were determined from the data by highlighting words or phrases from the text capturing key concepts. Notes were made on first impressions of the data and the codes were sorted into categories based on links. These categories organised the codes into meaningful clusters to derive themes. The advantage of this method of analysis is the ability to gain direct information without imposing preconceived categories, but it may fail to identify key categories. ${ }^{32}$

Semi-structured interviews were appropriate for this research which aims to "delve beneath the surface of superficial responses to obtain true meanings that individuals assign to events, and the complexities of their attitudes, behaviours and experiences". ${ }^{33}$ Interviews enable probing and clarification, to gain a deeper understanding into behaviours of mothers and reasons behind their infant-feeding decisions. The emphasis of confidentiality encouraged open discussion of sensitive information.

This method of data collection enabled sufficient information to be obtained. The semi-structured format allowed the participant to lead the direction of the interview whilst covering the topic guide. Qualitative research enables exploration of sensitive areas, particularly where an in-depth understanding of attitudes and experiences is desired. Consistency was difficult to maintain due to the semi-structured nature of the interviews, and the presence of the translator may have affected the data. ${ }^{34}$

Local ethical approval was gained from the Medical Research and Ethics Committee (MREC) by the Ministry of Health in Malaysia, and the Sarawak General Hospital. As mentioned, written informed consent was obtained by each participant prior to interview in Malay.

\section{RESULTS}

Many different themes presented themselves during these 17 interviews. Throughout the study, certain themes were emphasized by many mothers. Five major themes arising from the data will be discussed.

\section{(1) Positive attitudes towards breastfeeding}

Of note were the wholly positive maternal attitudes towards breastfeeding. All women were planning to exclusively breastfeed their babies for at least six months.

"For her, satisfaction. More for bonding, she
feels love for the baby. You feel that you are
a real mother if you breastfeed."

Most of the mothers also described positive attitudes towards breastfeeding among family members and medical staff.

"She has all the support from the health clinic, from the husband, from the in-laws where she stays, they all encourage her to breastfeed." 
In addition to familial support, all the interviewees did not feel any negative attitudes or stigmatisation towards breastfeeding in society. Breastfeeding appears acceptable and the norm in society.

"She just has to do it, because her friends are also doing it. Following the trend you know; trend breastfeeding, trend not breastfeeding."

Overall, most mothers had positive attitudes towards breastfeeding and felt supported in this by their friends and family. They feel that society as a whole is respectful of mothers' breastfeeding and that there is no associated stigma. Although clearly this positivity is beneficial, it does raise the question of how women may be treated if they are not able to breastfeed.

\section{(2) Lack of knowledge relating to exclusive breastfeeding}

All mothers were aware that exclusive breastfeeding is advantageous, but only five mothers mentioned more than two benefits of breastfeeding. The main advantages listed were bonding between mother and child, immunity and reducing the risk of breast cancer.

\footnotetext{
"She feels a lot of good thing about breastfeeding, that's what she knows, only the good thing."
}

When asked about problems with breastfeeding, the main issue is the worry that they will not have enough milk, which is discussed below. Only one interviewed mother mentioned a disadvantage, "she finds it very painful, full breasts".

Despite women feeling that breastfeeding is beneficial, evidently, they do not fully comprehend the advantages and disadvantages in order to come to an educated decision. Nine mothers felt unprepared, with a lack of knowledge about breastfeeding.

"Not enough knowledge. She says that nobody teaches her yet on how to position the baby"

"She is not sure about lying down position...To her, the baby might choke. She need to learn more."
Other mothers felt that they had enough knowledge about breastfeeding but would appreciate further education with other aspects.

"She said breastfeeding is enough, but then they should have taught her something else related to breastfeeding but not breastfeeding. Related topics. Maybe baby care."

The interviews highlight a need for better breastfeeding education to enable women to make an informed choice for themselves and their infant. Mothers' knowledge comes mostly from the health clinics in addition to magazines, friends and family. Evidently, health professionals primarily require breastfeeding education in order to disperse it to mothers.

\section{(3) Fear of insufficient milk}

Despite relative positivity when talking about breastfeeding, some new mothers are fearful of not having enough milk to satisfy the baby.

"She's worried that the colostrum might not be enough for the baby... They always feel that when the breast is soft, there is not much milk, so psychologically they will say, I don't have breast milk."

"Her problem is she can foresee already baby refuse to suck, not enough breast milk, breasts become engorged, that will make the mother change to formula."

Nine out of the eleven mothers with previous children stopped breastfeeding due to feeling that they did not have enough breast milk to satisfy their babies.

"She feel she got less milk production, and then the baby already taking something else...because she is working she only gives night time feeds so I think the milk becoming less and less production so I think she just stop."

"She tries to breastfeed, but no milk coming out. Her problem is she is worried now because her baby not pass urine, not pass 
motion, because now she is worried there is not enough breast milk, they say the baby don't feed enough."

Many mothers seem concerned about running out of breast milk, often leading to discontinuation of breastfeeding amongst mothers. Further education and adequate support may dispel these anxieties and enable mothers to understand that if they cannot breastfeed exclusively, there are other options for them.

\section{(4) Improving awareness and knowledge of breastfeeding}

Most mothers suggested an educational improvement to encourage exclusive breastfeeding. Suggestions focused on education in schools, wider advertisement of breastfeeding and breastfeeding counselling. Some suggested targeting breastfeeding education and support towards new mothers in particular.

"She wants counselling session for young mothers especially, regarding breastfeeding...There are lots of teenage mothers."

Other mothers suggested more widely broadcasted breastfeeding education as the publicity would enable mothers to consider their options and may reduce any negative societal perceptions.

"If public education can be given at school, you know the images, people breastfeeding"

"On this (World Breastfeeding) day we should all be aware of breastfeeding, and we should put up something so that everybody is aware...She would like more sessions on health education on breastfeeding in the community."

The majority of mothers felt that there was room for educational improvement. It is apparent that public education is required from a young age to increase breastfeeding awareness amongst all the population and community in order to better support mothers.
(5)

Improving barriers to breastfeeding in the workplace

Maternal employment was cited as a barrier to breastfeeding. Only one interviewee seemed content with her workplace's regulations regarding breastfeeding, but even she suggested an improvement:

"She won't be long in the office, so it is quite easy for her. She says she can bring baby to the workplace... it would be better if there is a place they can sit very happily, where they can do breastfeeding in the workplace."

The majority of mothers were dissatisfied with the situation at their workplace. Suggested improvements include workplace nurseries, flexihours enabling breastfeeding in breaks, providing an area for breast milk expression and a fridge for storage.

"She feels that there should be change in the workplace, probably giving them...flexitime to come and to go back just to breastfeed the baby, but it depends on her superior."

"Maybe there should be a place for them to do the EBM (expressed breast milk) in the office, also a place for them to store the EBM in the office, because at the moment she doesn't have any."

One mother wished to exclusively breastfeed, but time restrictions prevented expressing milk at work. Her milk dried up so she had to switch to infant formula:

"After she goes back to work, she is still breastfeeding but she has to mix... after one month exclusive breastfeeding, and she just has to put onto infant formula, she only breastfeeds when she's back home."

Modifications in the workplace are required to enable mothers to exclusively breastfeed for up to six months. Maternity leave lasts between one and three months in Malaysia and therefore workplaces 
should provide facilities to encourage breastfeeding at work. This is an essential requirement if we are to increase the rates of exclusive breastfeeding amongst working mothers.

\section{DISCUSSION}

All new mothers were positive about breastfeeding and were planning to exclusively breastfeed. Societal attitudes were also positive; no-one discouraged breastfeeding and there was no felt stigma. Positive attitudes towards breastfeeding have been reflected in the USA where most students believe that embarrassment prevents mothers from breastfeeding publicly. ${ }^{35}$ Although a contradictory study highlights neutral breastfeeding attitudes and low support for breastfeeding in public. $^{36}$ Concurrently, societal stigma is noted in Malawi, ${ }^{37}$ Lebanon $^{38}$ and the $\mathrm{UK}^{39}$. Despite stigma being cited as a negative aspect of breastfeeding, more positive aspects have been cited than negative, ${ }^{40}$ as demonstrated in this study. Efforts should be made to dispel negative societal perceptions of breastfeeding as women are more likely to continue breastfeeding if they feel comfortable doing so in public. ${ }^{41}$

As suggested by previous evidence, ${ }^{22}$ a deficit exists in certain aspects of knowledge regarding breastfeeding. The results show that most mothers are knowledgeable concerning benefits of breastfeeding, but they do not fully comprehend positioning, expressing and storing breast milk. These findings concur with previous evidence from Malaysia; whilst $98 \%$ of mothers were aware that breast milk was good for their baby's health and strengthens bonding, $66 \%$ threw away the colostrum before feeding due to believing it was dirty. ${ }^{23}$

The feeling of inadequate breast milk production is an influential factor regarding discontinuing breastfeeding in Malaysia. ${ }^{24-26}$ This anxiety is echoed in this study, with seven out of the eleven mothers with previous children discontinuing breastfeeding due to feeling they had insufficient milk. These anxieties are apparent amongst new mothers prior to initiating breastfeeding. Evidence shows that it is unlikely for mothers to run out of milk if they breastfeed correctly. ${ }^{42}$ Provision of adequate information on baby feeding behaviours, correct positioning and normal changes in a woman's body during breastfeeding in addition to reassurance prior to delivery may encourage self-confidence in preparation for breastfeeding.

Thirteen mothers in this study obtained information regarding breastfeeding from the hospital or clinic. Evidently a more global method of data dispersal is required, and adequate training of healthcare professionals to enable better information provision to mothers. Methods to improve knowledge were suggested; some interviewees believe mothers should attend counselling sessions and breastfeeding courses, others think campaigns and education in the community would be more effective.

Previous evidence recommends individualised care, practical help with breastfeeding, ante-natal education and post-natal support to increase breastfeeding rates and continuation. ${ }^{43-45}$ Combined professional and peer support effectively improves breastfeeding continuation. ${ }^{46}$ Staff trained by the Baby-Friendly Initiative demonstrate increased breastfeeding continuation rates and improved consistency among team members. ${ }^{47}$ The staff in Malaysian hospitals should therefore now be well equipped to educate mothers. Practical sessions with plenty of support and information leaflets to take away are recommended.

In terms of society education, introducing breastfeeding education in schools was suggested. In the UK, primary children have been shown to be receptive to new ideas about infant feeding, but interventions must be evidence-based and evaluated. ${ }^{48}$ The media should be involved to encourage widespread dissemination of exclusive breastfeeding in the public domain, reducing stigma and negative attitudes.

Another overriding reason why mothers terminate breastfeeding in Malaysia is maternal employment. ${ }^{24,26}$ This is highlighted by the results from this study. Maternity leave is only three months, and most workplaces do not provide facilities for continued breastfeeding at work. Research conducted in Australia demonstrates that by allowing paid parental leave for 10 months, mothers have sufficient time to breastfeed and develop optimal maternal-infant attachment. ${ }^{49}$ The optimal strategy enables breastfeeding during the working day, whether by providing on-site child care or flexible time to go the infant during the day. ${ }^{50}$ Improvements suggested in this study, as in previous 
research, focus on providing fridges and areas to express breast milk.

A study conducted in Singapore highlights modifiable factors to encourage exclusive breastfeeding; awareness of breastfeeding benefits, advice from healthcare professionals, and workplace policies. ${ }^{51}$ These factors are emphasized in this study and promotion of exclusive breastfeeding should address these areas. Data from this study demonstrate a requirement for further education regarding positioning, infant feeding behaviours, expressing and storing breast milk. This would be effectively achieved by practical teaching sessions in hospitals and by providing leaflets and posters in other public areas such as supermarkets. It should be a requirement for all workplaces to have a fridge to store EBM and an area in which to express.

This study was limited by certain factors. Primarily, the primary translator was the breastfeeding nurse for the hospital, so researcher bias may have been present due to her desire to emphasize positive aspects of the hospital's policies. Secondly, the use of a translator made it difficult to capture and therefore analyse participant's exact words, as required for qualitative studies. However, this was necessary as the primary investigator did not speak Malay. Thirdly, by using convenience sampling, the patient sample is susceptible to selection bias and may not be representative. Finally, the use of a translator may cause sensitivity bias, and the language barrier occasionally prevented the correct meaning of questions being posed. In future studies, it would be recommended for the primary investigator to speak Malay and therefore reduce the influential aspect of using a translator, which was necessary in this research.

\section{CONCLUSION}

Five main themes were identified regarding exclusive breastfeeding in Malaysia: 1) positive attitudes towards breastfeeding, 2) lack of knowledge, 3) fear of insufficient milk, 4) methods to improve awareness and knowledge, 5) improvements in the workplace. Improvements to encourage breastfeeding were identified, both in the workplace and in education. In order to tackle the low breastfeeding rates, the Malaysian government could introduce policies as suggested to improve knowledge and encourage breastfeedingfriendly employment. By increasing exclusive breastfeeding rates, both maternal and infant health should improve, thereby positively impacting other sustainable development goals.

\section{CONFLICTING INTERESTS}

The author declares that they have no conflicting interests.

\section{ACKNOWLEDGEMENTS}

I would like to acknowledge Breastfeeding Nurse Merik Salim for her aid in translating and practical aspects of conducting this research. I would like to acknowledge $\operatorname{Dr} \mathrm{P}$ Giddings and $\mathrm{Dr}$ Wong for their supervision during this project. I am grateful to the staff of the maternity ward for their co-operation during this project.

I am grateful to the University of Birmingham Onnesley Elective grant, the Medical and Dental Student's Trust and the Medical Women's Federation for their contributions to the funding of this research project.

\section{REFERENCES}

1. Kelleher DK, Duggan C. Breast milk and breastfeeding in the 1990s. Curr Opin Paediatr 1999 Jun;11(3):275-80.

2. Oddy WH. Breastfeeding protects against illness and infection in infants and children: a review of the evidence. Breastfeed Rev 2001 Jul;9(2):11-8.

3. Kramer MS, Kakuma R. Optimal duration of exclusive breastfeeding. Cochrane Database Syst Rev 2002;(1):CD003517.

4. World Health Organization (2002). The optimal duration of exclusive breastfeeding: $A$ systematic review. World Health Organization, Geneva.

5. Victora CG, Bahl R, Barros AJ, França GV, Horton S, Krasevec J et al. Breastfeeding in the $21^{\text {st }}$ century: epidemiology, mechanisms, and lifelong effect. Lancet 2016 Jan 30; 387 (10017):475-90.

6. DaVanzo J, Sine J, Peterson C, Haaga J. Reversal of the decline in breastfeeding in peninsular Malaysia? Ethnic and educational differences and data quality issues. Soc Biol 1994 SpringSummer;41(1-2):61-77. 
7. Haaga JG. Evidence of a reversal of the breastfeeding decline in peninsular Malaysia. Am J Public Health 1986 Mar;76(3):245-51.

8. King J, Ashworth A. Historical review of the changing pattern of infant feeding in developing countries: the case of Malaysia, the Caribbean, Nigeria and Zaire. Soc Sci Med 1987;25(12):1307 -20 .

9. Manderson L. Bottle feeding and ideology in colonial Malaya: the production of change. Int J Health Serv 1982;12(4):597-616.

10. Koh TH. Breastfeeding among the Chinese in four countries. J Trop Pediatr 1981 Apr;27 (2):88-91.

11. Serva V, Karim H, Ebrahim GJ. Breast-feeding and the urban poor in developing countries. $J$ Trop Pediatr 1986 Jun;32(3):127-9.

12. Chua S, Viegas OA, Ratnam SS. Three decades of breast-feeding trends in Singapore. Asia Pac Popul J 1990 Mar;5(1):125-34.

13. World Health Organization (2003). Global strategy for infant and young child feeding. World Health Organization, Geneva.

14. Institute for Public Health, Ministry of Health Malaysia: Ekslusif, Panduan Penyusuan Susu Ibu, 6 Bulan Pertama Hanya Susu Ibu. Kuala Lumpur: Ministry of Health Malaysia; 2005.

15. World Health Organisation and UNICEF (2009). Baby-Friendly Hospital Initiative; Revised, updated and expanded for integrated care. World Health Organisation, Geneva.

16. United Nations Children's Fund (UNICEF). Breastfeeding and complementary feeding can save close to 2 million lives yearly. UNICEF Press 2005 July 29. [http:/ /www.unicef.org/ malaysia/media_4953.html].

17. Fatimah S Jr, Siti Saadiah HN, Tahir A, Hussain Imam MI, Ahmad Faudzi Y. Breastfeeding in Malaysia: Results of the third national health and morbidity survey (NHMS III). Malays J Nutr 2010 Aug;16(2):195-206.

18. Allport, G. Attitudes, in "A Handbook of Social Psychology" (C. Murchison, Ed.), pp. 798-844. Clark Univ. Press, Worcester, Mass., 1935.

19. Schrader PG, Lawless KA. The knowledge, attitudes \& behaviours approach how to evaluate performance and learning in complex environments. Performance Improvement 2004 Sept; 43(9): 8-15.

20. Tengku Ismail TA, Sulaiman Z, Jalil R, Wan Muda WM, Nik Man NN. Breast milk expression among formally employed women in urban and rural Malaysia: a qualitative study. Int Breastfeed J 2012 Aug 29;7(1):11.

21. Kandiah M, Ooi Guat San. Infant feeding study: knowledge and attitudes of pregnant women. Malays J Reprod Health 1984 Dec;2(2):96-104.

22. Tengku Ismail TA, Sulaiman Z. Reliability and validity of a Malay-version questionnaire assessing knowledge of breastfeeding. Malays $J$ Med Sci 2010 Jul;17(3):32-9.

23. Yusof YA. Mazlan M, Ibrahim N, Jusoh NM. Infant feeding practices and attitudes of mothers in Kelantan towards breastfeeding. Med J Malaysia 1995 Jun;50(2):150-5.

24. Sinniah D, Chon FM, Arokiasamy J. Infant feeding practices among nursing personnel in Malaysia. Acta Paediatr Scand 1980 Jul;69 (4):525-9.

25. Koh TH. Breastfeeding in Sarawak. Br Med J 1980 Jan 12;280(6207):95-96.

26. Chia SF. A survey of breast feeding practices in infants seen in general practice. Med J Malaysia 1992 Jun;47(2):134-8.

27. Tan KL. Factors associated with exclusive breastfeeding among infants under six months of age in peninsular Malaysia. Int Breastfeed $\mathrm{J}$ 2011 Feb;6(1):2.

28. Amin RM, Said ZM, Sutan R, Shah SA, Darus A, Shamsuddin K. Work related determinants of breastfeeding discontinuation among employed mothers in Malaysia. Int Breastfeed J 2011 Feb 22;6(1):4.

29. Chye JK, Lim CT. Breastfeeding at 6 months and effects on infections. Singapore Med J 1998 Dec;39(12):551-6.

30. Ting S, Rose L. Ethnic language use and ethnic identity for Sarawak indigenous groups in Malaysia. Oceanic Linguistics 2014; 53 (1): 92109.

31. Green J, Thorogood N. Qualitative methods for health research. Sage; 2018 Feb 26: page 15.

32. Hseih HF, Shannon SE. Three approaches to qualitative content analysis. Qual Health Res 2005 Nov;15(9):1277-1288

33. Bowling A. Research Methods in Health: Investigating health and health services. $3^{\text {rd }}$ ed. OUP McGraw Hill 2009:407-409.

34. Bowling A. Research Methods in health: Investigating health and health services. $3^{\text {rd }}$ ed. OUP McGraw Hill 2009:480-382.

35. Forrester IT, Wheelock G, Warren AP. Assessment of student's attitudes toward 
breastfeeding. J Hum Lact 1997 Mar;13(1):33-7.

36. Kavanagh KF, Lou Z, Nicklas JC, Habibi MF, Murphy LT. Breastfeeding knowledge, attitudes, prior exposure, and intent among undergraduate students. J Hum Lact 2012 Jun

6. [Epub ahead of print]

37. Østergaard LR, Bula A. "They call our children "Nevirapine babies?" “: A qualitative study about exclusive breastfeeding among HIV positive mothers in Malawi. Afr J Reprod Health 2010 Sep;14(3):213-22.

38. Nabulsi $M$. Why are breastfeeding rates low in Lebanon? A qualitative study. BMC Pediatr 2011 Aug;30:11:75.

39. Brown A, Raynor P, Lee M. Healthcare professionals' and mothers' perceptions of factors that influence decisions to breastfeed or formula feed infants: a comparative study. $J$ Adv Nurs 2011 Sep;67(9):1993-2003.

40. Kendall-Tackett KA, Sugarman M. The social consequences of long-term breastfeeding. $J$ Hum Lact 1995 Sep;11(3):179-83.

41. Stuebe AM, Bonuck K. What predicts intent to breastfeed exclusively? Breastfeeding knowledge, attitudes and beliefs in a diverse urban population. Breastfeed Med 2011 Dec;6 (6):413-20.

42. Kent JC, Prime DK, Garbin CP. Principles for maintaining or increasing breast milk production. J Obstet Gynaecol Neonatal Nurs 2011 Dec 12 [Epub ahead of print].

43. Joanna Briggs Institute. Best Practice Information Sheet: Women's perceptions and experiences of breastfeeding support. Nurs Health Sci 2012 Mar;14(1):133-5.

44. Duffy EP, Percival P, Kershaw E. Positive effects of an antenatal group teaching session on postnatal nipple pain, nipple trauma and breastfeeding rates. Midwifery 1997 Dec;13 (4):189-96.

45. Kaunonen M, Hannula L, Tarkka MT. A systematic review of peer support interventions for breastfeeding. J Clin Nurs 2012 Jul;21(1314):1943-54.

46. Sheehan A. A comparison of two methods of antenatal breast-feeding education. Midwifery 1999 Dec;15(4):274-82.

47. Ingram J, Johnson D, Condon L. The effects of Baby Friendly Initiative training on breastfeeding rates and the breastfeeding attitudes, knowledge and self-efficacy of community health-care staff. Prim Health Care
Res Dev 2011 Jul;12(3):266-75.

48. Angell C, Alexander J, Hunt JA. How are babies fed? A pilot study exploring primary school children's perceptions of infant feeding. Birth 2011 Dec;38(4):346-53.

49. Cooklin AR, Rowe HJ, Fisher JR. Paid parental leave supports breastfeeding and mother-infant relationship: a prospective investigation of maternal postpartum employment. Aust $\mathrm{N} Z \mathrm{~J}$ Public Health 2012 Jun;36(3):249-56.

50. Fein SB, Mandal B, Roe BE. Success of strategies for combining employment and breastfeeding. Paediatrics 2008 Oct;122 Suppl 2:S56-62.

51. Foo LL, Quek SJ, Ng SA, Lim MT, DeurenbergYap M. Breastfeeding prevalence and practices among Singaporean Chinese, Malay and Indian mothers. Health Promot Int 2005 Sep;20(3):22937. Epub 2005 Apr 6. 
